\title{
Water Withdrawals, Use, Discharge, and Trends in Florida, 2000
}

Scientific Investigations Report 2004-5151
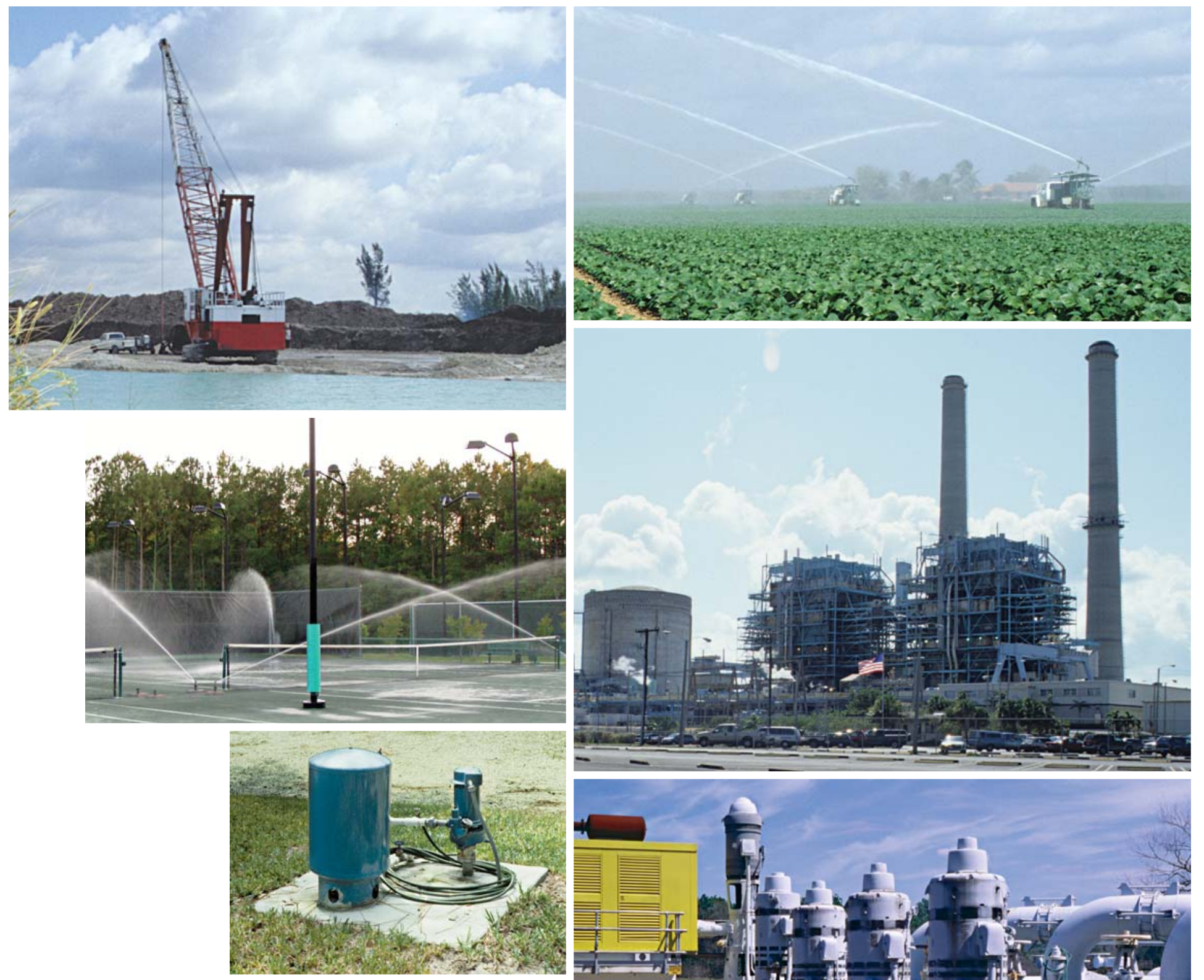

U.S. Department of the Interior U.S. Geological Survey

Prepared in cooperation with the Florida Department of Environmental Protection

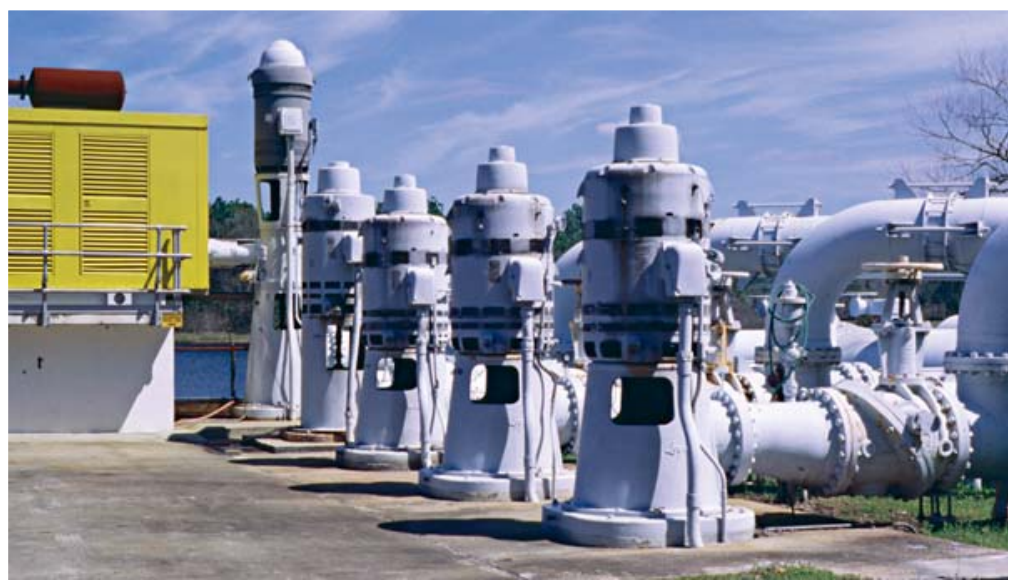

